\title{
Groundwater prospecting by the inversion of cumulative data of Wenner-Schlumberger and dipole-dipole arrays: A case study at Turamdih, Jharkhand, India
}

\author{
Abhay Kumar Bharti ${ }^{1}$, S K Pal ${ }^{2}$, , Saurabh $^{2}$, K K K Singh ${ }^{1}$, P K Singh ${ }^{1}$, \\ Amar Prakash ${ }^{1}$ and $\mathrm{R}$ K TIWARY ${ }^{1}$ \\ ${ }^{1}$ Department of Environmental Assessment and Remediation, CSIR-CIMFR, Barwa Road, \\ Dhanbad 826 001, India. \\ ${ }^{2}$ Department of Applied Geophysics, Indian Institute of Technology (Indian School of Mines), \\ Dhanbad 826 004, India. \\ *Corresponding author.e-mail: sanjitism@gmail.com
}

MS received 7 February 2018; revised 8 October 2018; accepted 29 November 2018; published online 6 April 2019

The present study deals with groundwater prospecting in hardrock terrain. Initially, the Wenner-Schlumberger array and the dipole-dipole array data have been acquired using Syscal Junior Switch-48. Furthermore, data acquired using both arrays have been merged using Prosys-II data handling software for the inversion of the cumulative data for possible mapping of water-bearing fracture rock masses with different structural distribution in a complex geological environment. The data have been analysed using RES2DINV software, based on the smoothness constrained least-square technique. Two numbers of $2 \mathrm{D}$ electrical resistivity tomography profiles $\left(\mathrm{AA}^{\prime}\right.$ and $\left.\mathrm{BB}^{\prime}\right)$ have been selected over an official colony of the Turamdih uranium mine for groundwater prospecting, which is located at about $24 \mathrm{~km}$ west of Jaduguda, Jharkhand, India. High-resistivity features associated with a dyke-like structure have been delineated in both the profiles. Three low-resistivity features have been delineated as water saturated alluvium/aquifers in profile $\mathrm{AA}^{\prime}$. A low-resistivity feature associated with the water-saturated fracture zone has been identified in profile $\mathrm{BB}^{\prime}$, which is well correlated with the surficial location of an ephemeral channel at the bottom of the hill across the slope. It is observed that geoelectric sections generated by the inversion of cumulative data of both arrays provide superior results compared with the WennerSchlumberger and dipole-dipole arrays, separately.

Keywords. ERT; Wenner-Schlumberger; dipole-dipole; inversion of cumulative data; groundwater prospecting.

\section{Introduction}

Groundwater in hardrock terrain is a serious issue, which occurs in limited areal extent within secondary porosity generated by weathering, fracturing, jointing and faulting. In hardrock terrain, the fractured rocks are only the channel for water charging and transporting. These structural variations are scattered in the hard-rock areas (Yadav and Singh 2007). Unplanned drilling without suitable information regarding subsurface formation may lead to unsuccessful results. As the drilling is costly, geophysical methods are used for subsurface investigation. Thus, proper technique 
is a key factor for the optimised exploration of groundwater resources, which involves the mapping of source location, its depth, extension and optimised drill locations

There are different successful case studies on different integrated remote sensing and geographical information system techniques for targeting groundwater potential zones (Saraf and Chowdhury 1998; Biswas et al. 2012, 2013; Jha 2014). The depth of occurrence of groundwater zones and locations of well sites can be determined more effectively by the electrical resistivity method. The ground resistivity is related to various geological parameters such as the mineral and fluid content, porosity, degree of fracturing, the percentage of the fractures filled with groundwater and the degree of water saturation in the rock. Generally, deep resistivity sounding is the conventional technique used for groundwater exploration (Bhattacharya and Patra 1968; Zohdy et al. 1974; Telford et al. 1976; Parasnis 1986; Karous and Mares 1988; Giao et al. 2003; Kumar et al. 2007; Bhattacharya and Shalivahan 2016), which provides subsurface information of the centre point of a profile. With the advancement of recent technology, the electrical resistivity tomography (ERT) method is being used for $2 \mathrm{D}$ subsurface imaging in terms of resistivity distribution. Recently, ERT method, a wellestablished tool, is being widely used for groundwater exploration (Krishnamurthy et al. 2003; Kumar et al. 2014, 2016) an environmental (Singh et al. 2004; Leucci 2006; Cardarelli et al. 2010; Banerjee et al. 2011; Mondal et al. 2013; Singh 2013b; Sarma 2014; Bharti et al. 2015, 2016a, b, c) study over different complex geological environments.

Several studies on groundwater exploration in hard-rock terrain have been successfully carried out using resistivity methods (Saxena et al. 2005; Dutta et al. 2006; Chandra et al. 2008; Mohammed 2011; Srivastava et al. 2012; Surinaidu et al. 2012; Kumar et al. 2014, 2016; Martínez-Moreno et al. 2014; Rai et al. 2015; Shishaye and Abdi 2016). The work by Kumar (2012) indicates the efficacy of the resistivity tomography technique for the mapping of a shallow anomaly including deeper groundwater resources in different geological terrain of hard-rock systems in various parts of India. Sharma and Baranwal (2005) used an integrated resistivity study comprising the VLF electromagnetic method; resistivity method and the selfpotential method for groundwater exploration over the hard-rock areas near Purulia, West Bengal, India. Yadav and Singh (2007) conducted gradient profiling and Schlumberger sounding, in which they have successfully delineated the water-bearing fractured formation over hard-rock areas. The present study was conducted in the official colony of the Turamdih uranium mine of Uranium Corporation of India Ltd. (UCIL), East Singhbhum, Jharkhand, India, which falls in the west-central part of the Singhbhum Shear Zone (figure 1). Initially, UCIL attempted the boring of tube wells several times in the official colony of the Turamdih uranium mine, most of which was unsuccessful. Thus, a stateof-the-art technique is required for groundwater prospecting.

\section{Geology of the study area}

The main rock types are quartzite, feldspathicschist, chlorite sericite, schist with magnetite, apatite and quartzite, which belong to the Dalbhum Formation of the Proterozoic age (Mishra and Johnson 2005). Uranium in the form of the mineral uraninite is disseminated within the schistose rocks and appears to follow the foliation planes. This mineralised $(\mathrm{Cu}-\mathrm{U})$ stretch is a part of the $160 \mathrm{~km}$ arcuate belt known as the Singhbhum Shear Zone, mainly known for its geological attributes and extensive mining activities. Chlorites-chist and feldspathic-quartzites-chist are the two major predominant litho-units hosting uranium mineralisation at Turamdih. The overlying quartzite horizon with the NW-SE elongation is devoid of mineralisation. Quartzite and sericite schists are in the hanging-wall and footwall horizons of uranium mineralisation, respectively. Central Ground Water Board (CGWB) India and Ministry of Drinking Water and Sanitation, India, conducted some studies based on different geomorphological, geological and geophysical approaches. These studies reveal that the groundwater occurrence and movement in this area are basically controlled by the prevailing morphology and intensity of structural discontinuities. The structures are the main controlling factors of the occurrence and movement of groundwater over the area.

\section{Methodology}

The Syscal Junior Switch 48 (IRIS Instrument) system has been used for ERT data acquisition (figure 2). ERT measurement involves the passing of electric current into the ground through two metallic electrodes and measuring the resulting voltage difference at two potential electrodes. 


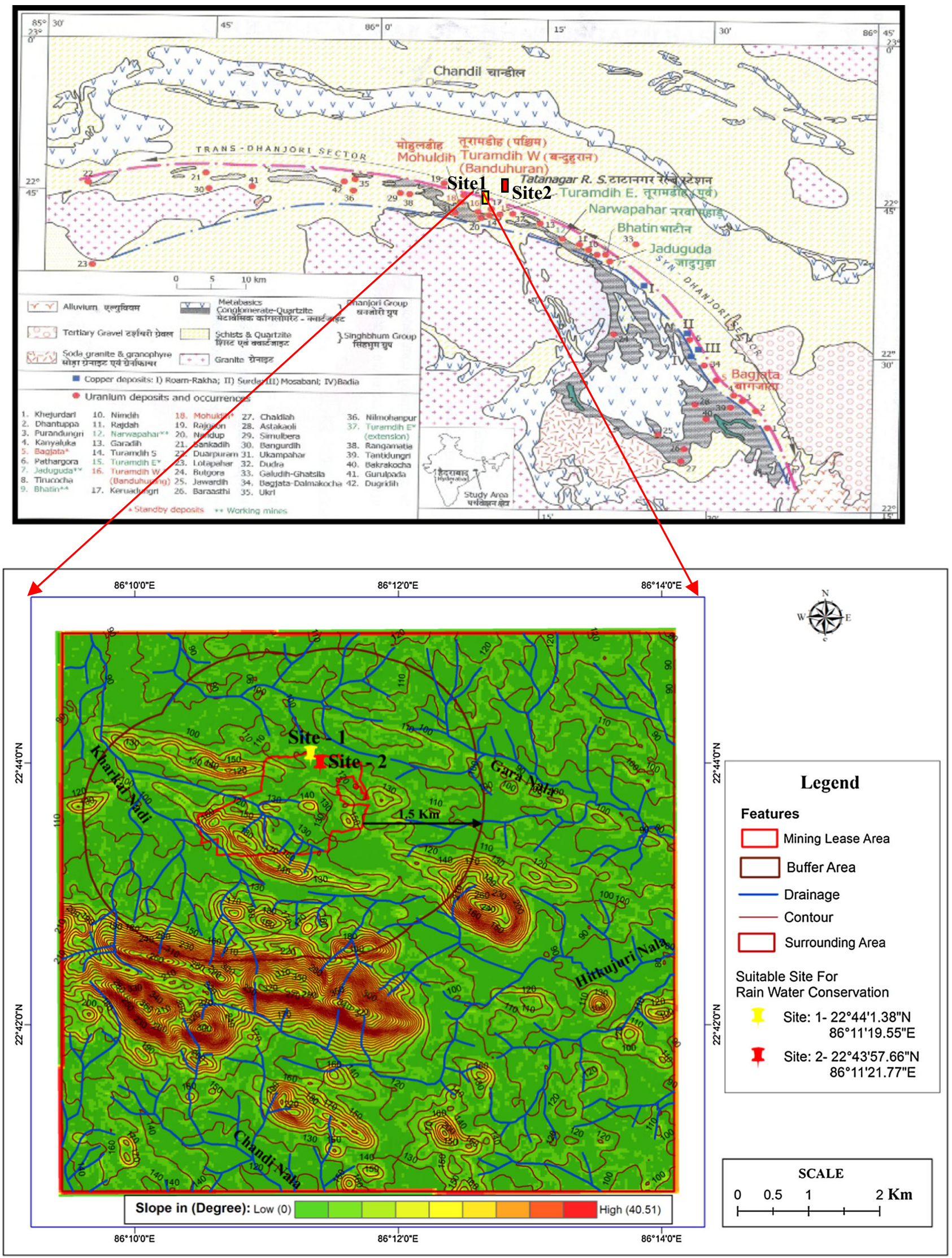

Figure 1. Location map of the study area. 


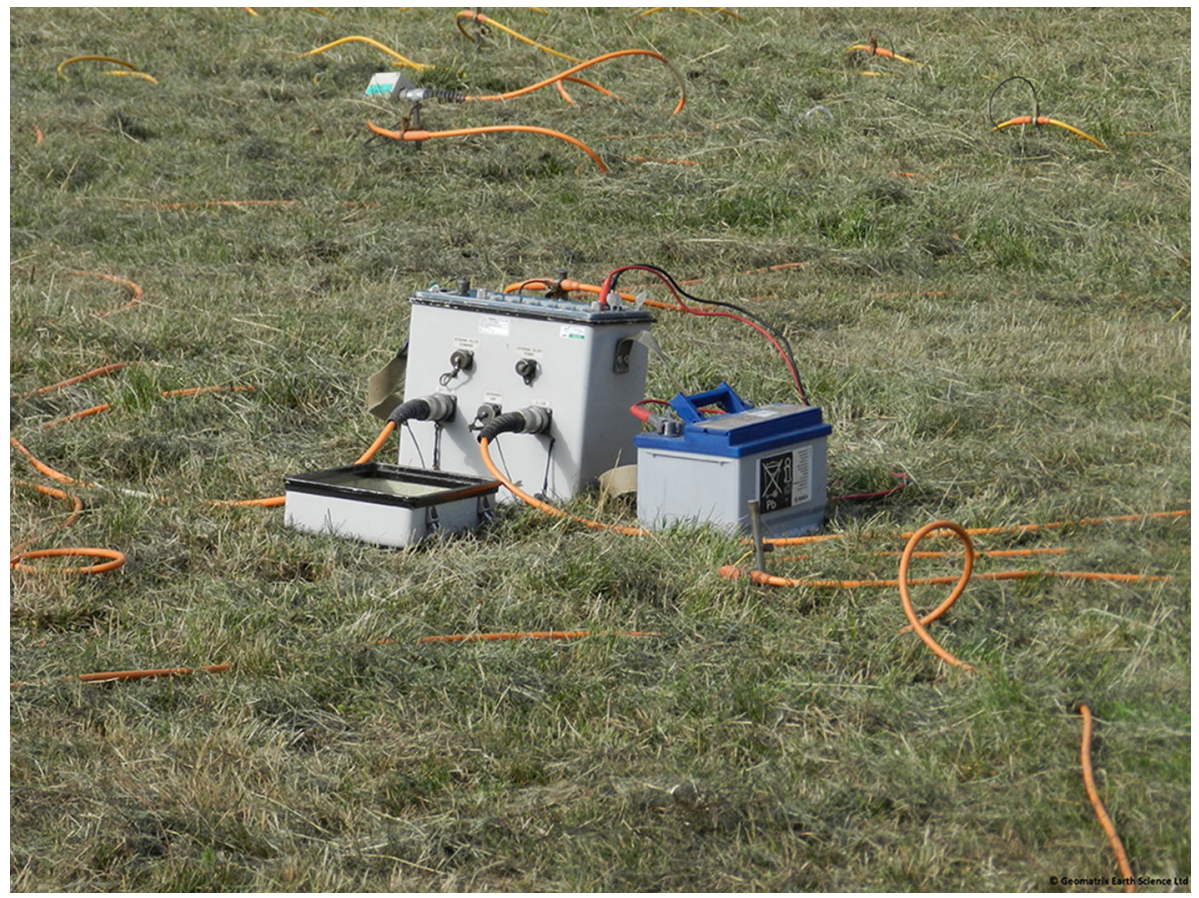

Figure 2. SYSCAL Jr Switch-48 (Iris Instrument) data-acquisition field setup using 48 electrodes.

From these measurements, the true resistivity of the subsurface is estimated. Such surveys are usually carried out using the number of electrodes (48 or more) in a series connected to a multicore cable. A microcomputer together with an electrodeswitching unit is used to automatically select the relevant four electrodes for each measurement. Apparent resistivity measurements are recorded sequentially and afterward, any quadripole (current and potential electrodes) sweep within the multielectrode array. As a result, high-definition pseudo-sections with dense sampling of apparent resistivity variation at shallow depths are obtained in a short time, which are then used for the generation of the $2 \mathrm{D}$ inverted true resistivity section. It allows for a detailed interpretation of $2 \mathrm{D}$ resistivity distribution in the subsurface formation. Generally, the vertical changes, i.e., horizontal features are well resolved in the Wenner array. Whereas the horizontal changes, i.e., narrow vertical structures are poorly detected in the Wenner array (Loke 1999). The Schlumberger array is moderately sensitive to both horizontal and vertical structures. Furthermore, the dipole-dipole array is good in mapping the vertical structures, such as dykes, cavities, etc. It is comparatively insensitive to vertical variations in the resistivity distribution, but much more sensitive to the difference in horizontal resistivity distribution. This array has better horizontal data coverage than the Wenner (Loke 1999).
Furthermore, inversion of the cumulative data of both arrays have been carried out for the mapping of water-bearing fracture rock masses with different structural distributions in complex geological environments (De la Vega et al. 2003; Stummer et al. 2004; Athanasiou et al. 2007; Bharti et al. 2016a, b; Das and Mohanty 2016). In theory, the combined inversion of data sets coming from different electrode arrays obtained over the same site along the same profile would allow us to combine the relative advantages of every array and thus to produce superior results (De la Vega et al. 2003; Stummer et al. 2004; Athanasiou et al. 2007). The resolution capability and signal-to-noise ratio are also optimised in the joint inversion of combined array data (Zhou and Greenhalgh 2000; Dahlin and Zhou 2006). De la Vega et al. (2003) presented combined inversion results of the dipole-dipole and Wenner array data obtained from a hydrocarbon contamination site. They recommended that combined inversion results have superior depth of investigation and better lateral resolution when compared to the inversion results obtained from each array separately.

\section{Results and discussions}

Two numbers of 2D ERT profiles, viz, $\mathrm{AA}^{\prime}$ and $\mathrm{BB}^{\prime}$ have been selected over an official colony 
of the Turamdih uranium mine, which is located at about $24 \mathrm{~km}$ west of Jaduguda, Jharkhand, India. Two electrode configurations, viz, WennerSchlumberger and dipole-dipole have been considered for mapping the fracture zone and the associated groundwater prospecting. ERT data have been acquired along profiles $\mathrm{AA}^{\prime}$ and $\mathrm{BB}^{\prime}$ covering lengths of 141 and $235 \mathrm{~m}$ with an electrode spacing of 3 and $5 \mathrm{~m}$, respectively. The WennerSchlumberger array collects 529 data points, whereas the dipole-dipole array collects 944 data points. Initially, each data set has been processed separately in Prosys-II data handling software for Syscal Junior Switch 48 IRIS Instrument. Furthermore, both data sets collected by WennerSchlumberger and dipole-dipole arrays have been merged using the Prosys-II data handling software. The Prosys II software allows to process data in various ways. Once a data file is open in the master window, data merging could be done using the 'Add' menu button in the Prosys II software. This resulted in a total number of 1473 data points with corresponding locations of the data points. Subsequently, the data sets have been examined through the extermination of bad data points filtering technique, which is then exported for processing using the RES2DINV software. During processing using Prosys-II data handling software, all data points were considered for analysis and inversion in the RES2DINV software. After the elimination of spicks and noises, data sets have been inverted based on the regularised least square optimisation technique using RES2DINV (Loke and Barker 1996). The inverted geoelectrical sections have been interpreted based on the variation of anomalous high- and low-resistivity values. The 2D ERT sections of profile $\mathrm{AA}^{\prime}$ and profile $\mathrm{BB}^{\prime}$ estimated using Wenner-Schlumberger and dipoledipole arrays and the inversion of the cumulative data of both arrays are shown in figures 3 and 4 respectively.

\subsection{Geoelectric model of profile $A A^{\prime}$}

As per the geoelectrical section of profile $\mathrm{AA}^{\prime}$ generated by the Wenner-Schlumberger array, two zones $\left(\mathrm{AL} 1^{\mathrm{ws}}\right.$ and $\mathrm{AL} 2^{\mathrm{ws}}$ ) of water saturated alluvium/aquifer zone have been delineated near a reduced distance $(\mathrm{RD})$ of about $7-42 \mathrm{~m}\left(\mathrm{AL}^{\mathrm{ws}}\right.$ and 75-130 m AL2 ${ }^{\mathrm{ws}}$ ) with relatively low resistivity of about $30-80 \Omega \mathrm{m}$ at the depth of about $3-14 \mathrm{~m}$ (figure 3a). A prominent signature of relatively high resistive fractured rock/weathered rock
$\left(\mathrm{AH} 1^{\mathrm{ws}}\right)$ at $\mathrm{RD}$ of $66-86 \mathrm{~m}$ with the depth of about 14-25 $\mathrm{m}$ has been identified with a resistivity of about 250-500 $\Omega \mathrm{m}$.

Three zones of a moist soil/water saturated alluvium/aquifer have been (figure $3 \mathrm{~b}$ of profile $\mathrm{AA}^{\prime}$ which is estimated based on the dipole-dipole array. These are near the RD of about (i) 6-48 $\mathrm{m}\left(\mathrm{AL} 1^{\mathrm{dd}}\right)$ with a depth range of $2-18 \mathrm{~m}$, (ii) 72 $130 \mathrm{~m} \mathrm{AL}^{\mathrm{dd}}$ ) with a depth range of $3-14 \mathrm{~m}$ and (iii) 61-69 $\mathrm{m}$ (AL3 ${ }^{\mathrm{dd}}$ ) with a depth range of $17-$ $24 \mathrm{~m}$, all having relatively low resistivity of about $10-60 \Omega \mathrm{m}$. There is hardly any prominent signature associated with hard rock near RD $72 \mathrm{~m}$.

Additionally, a 2D geoelectrical model of profile $\mathrm{AA}^{\prime}$ have been estimated by the inversion of the cumulative data of both dipole-dipole and Wenner-Schlumberger data sets, as shown in figure 3c. Three broad zones of moist soil/water saturated alluvium/aquifer have been delineated in the 2D geoelectric section (figure $3 \mathrm{c}$ ) of profile $\mathrm{AA}^{\prime}$ estimated by the inversion of the cumulative data of both arrays These are near the RD of about (i) 6-48 $\mathrm{m}\left(\mathrm{AL}^{\mathrm{c}}\right)$ with a depth range of 2-19 $\mathrm{m}$, (ii) $72-130 \mathrm{~m}\left(\mathrm{AL}^{\mathrm{c}}\right)$ with a depth range of $3-15 \mathrm{~m}$ and (iii) $61-69 \mathrm{~m}\left(\mathrm{AL3}^{\mathrm{C}}\right)$ with a depth range of $16-26 \mathrm{~m}$, all having relatively low resistivity of about $10-60 \Omega \mathrm{m}$. A prominent signature of relatively high-resistive $\left(\mathrm{AH}^{\mathrm{c}}\right)$ rock/fractured rockweathered rock/dyke like structure at $\mathrm{RD}$ of about $70 \mathrm{~m}$ at a depth of about $10 \mathrm{~m}$ has been identified with resistivity of about $500 \Omega \mathrm{m}$. The bed rock with high-resistivity signature has been delineated in both the $2 \mathrm{D}$ geoelectrical models of profile $\mathrm{AA}^{\prime}$ estimated by the dipole-dipole array and inversion of cumulative data of both arrays.

\subsection{Geoelectric model of profile $B B$}

The traverse of profile $\mathrm{BB}^{\prime}$ was taken at the bottom of a hill slope across an ephemeral channel. Three layered formation: (i) moist soil/water saturated alluvium with average thickness of $15 \mathrm{~m}$ having relatively low resistivity of about $2-200 \Omega \mathrm{m}$, (ii) weathered rock/fractured rock with average thickness of $4 \mathrm{~m}$ having moderate resistivity of about $200-400 \Omega \mathrm{m}$ and (iii) bedrock with average thickness of $9 \mathrm{~m}$ having high resistivity of about 500-2000 $\Omega \mathrm{m}$; have been delineated in the $2 \mathrm{D}$ geoelectrical model of profile $\mathrm{BB}^{\prime}$ based on the Wenner-Schlumberger array (figure 4a). A signature of quite low resistivity of about $1-17 \Omega \mathrm{m}$ has been identified between RD of about 137-144 m 

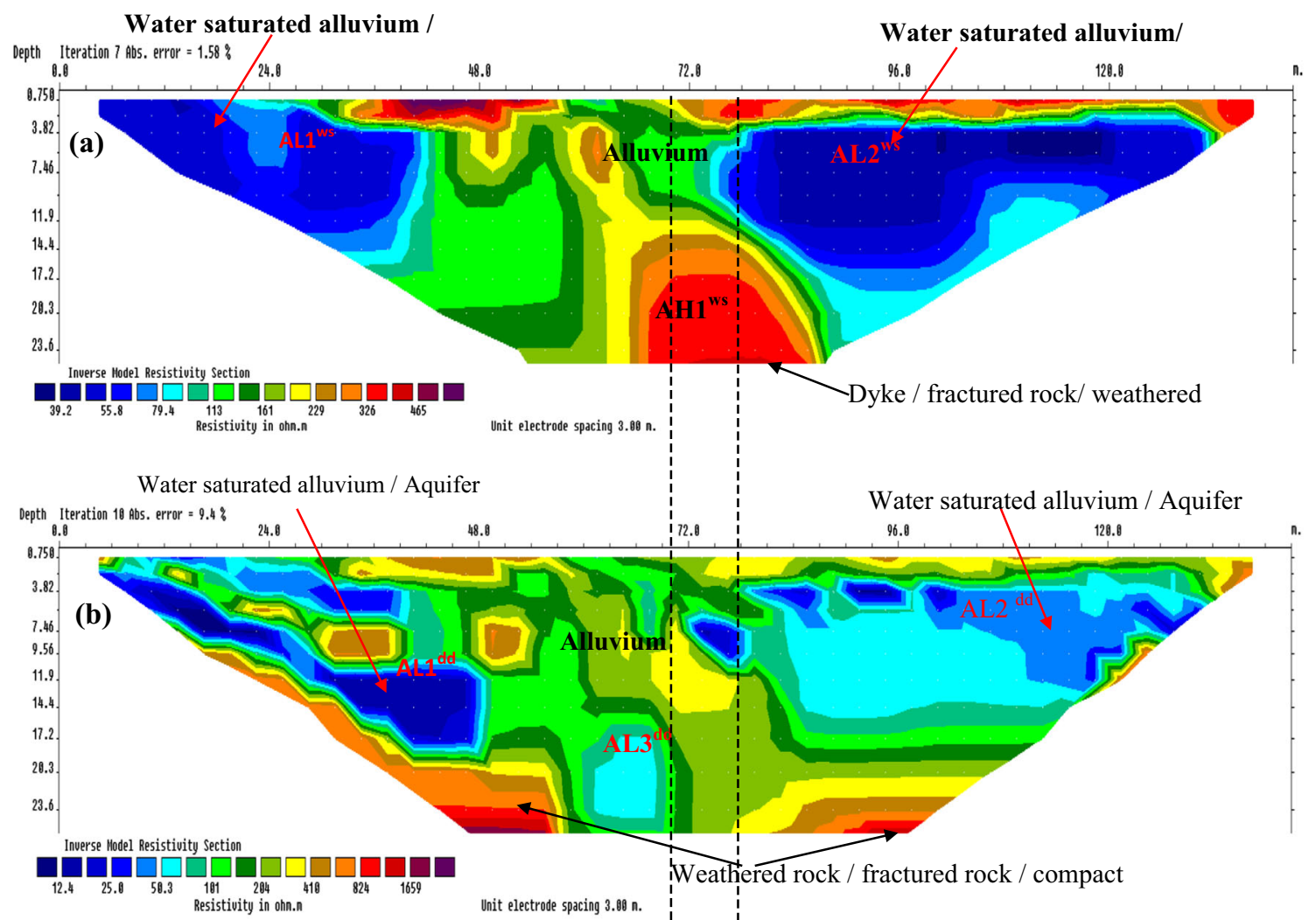

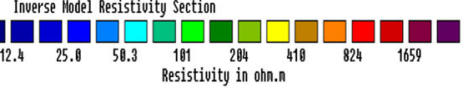

nit electrode spacing $3.00 \mathrm{n}$

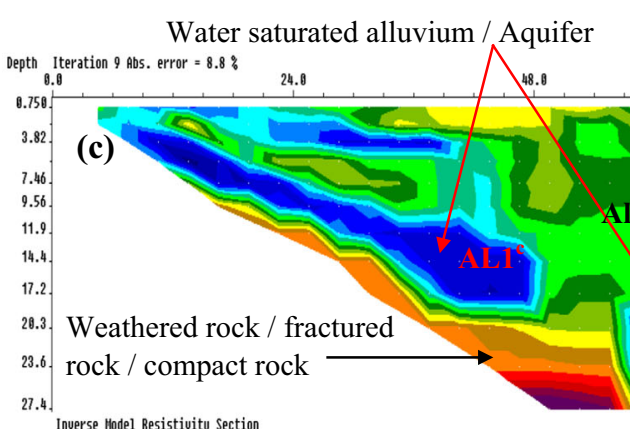

Inverse Hodel Resistivity Section

Unit electrode spacing 3.98 .

Water saturated alluvium/ Aquifer

$96.8 \quad-\quad 120.8$

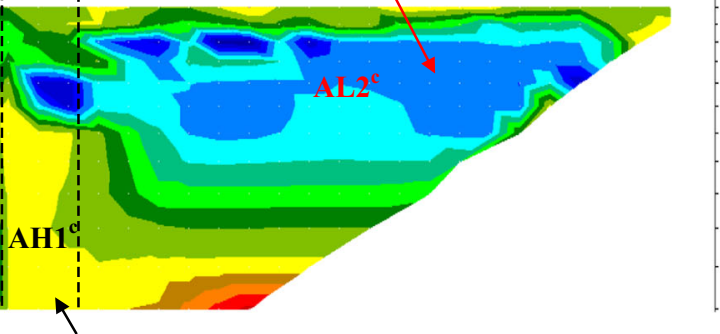

Dyke / fractured rock/ weathered rock

Figure 3. 2D ERT section along profile $\mathrm{AA}^{\prime}$ over the lower ground near Basti: (a) Wenner-Schlumberger array, (b) dipole-dipole array and (c) inversion of cumulative data of both arrays with a quality factor 5 .

$\left(B L 1^{\text {ws }}\right)$ with a depth range of $3-15 \mathrm{~m}$ within the first layer

A prominent signature of low resistivity of about $2-12 \Omega \mathrm{m}$ has been identified in a $2 \mathrm{D}$ geoelectrical model of profile $\mathrm{BB}^{\prime}$ based on the dipoledipole array figure $4 \mathrm{~b}$, between the $\mathrm{RD}$ of about 135-146 m (BL1 $\left.{ }^{\text {ws }}\right)$ with a depth range of 4-19 m. This is further spreading out to the greater depth of about $41 \mathrm{~m}$ with a larger horizontal expansion. In addition, a high-resistivity signature $\mathrm{BH}^{\mathrm{dd}}$ of about $400 \Omega \mathrm{m}$ associated with a rock/fractured rock/weathered rock/dyke like structure between
RD of about 110-130 $\mathrm{m}$ and a depth of about $19 \mathrm{~m}$ has also been identified

Furthermore, two noticeable signatures of (i) quite low resistivity of about $3-15 \Omega \mathrm{m}$ between $\mathrm{RD}$ of about $135-146 \mathrm{~m}\left(\mathrm{BL1}^{\mathrm{c}}\right)$ with a depth range of $3-24 \mathrm{~m}$, which is further continuing to a greater depth of about $44 \mathrm{~km}$ with a larger horizontal expansionand (ii) a high-resistivity signature $\left(\mathrm{BH}^{\mathrm{c}}\right)$ of about $400 \Omega \mathrm{m}$ between $\mathrm{RD}$ of about 110-130 m with a depth of about $19 \mathrm{~m}$ have also been identified in the $2 \mathrm{D}$ geoelectrical model of profile $\mathrm{BB}^{\prime}$ estimated by the inversion 

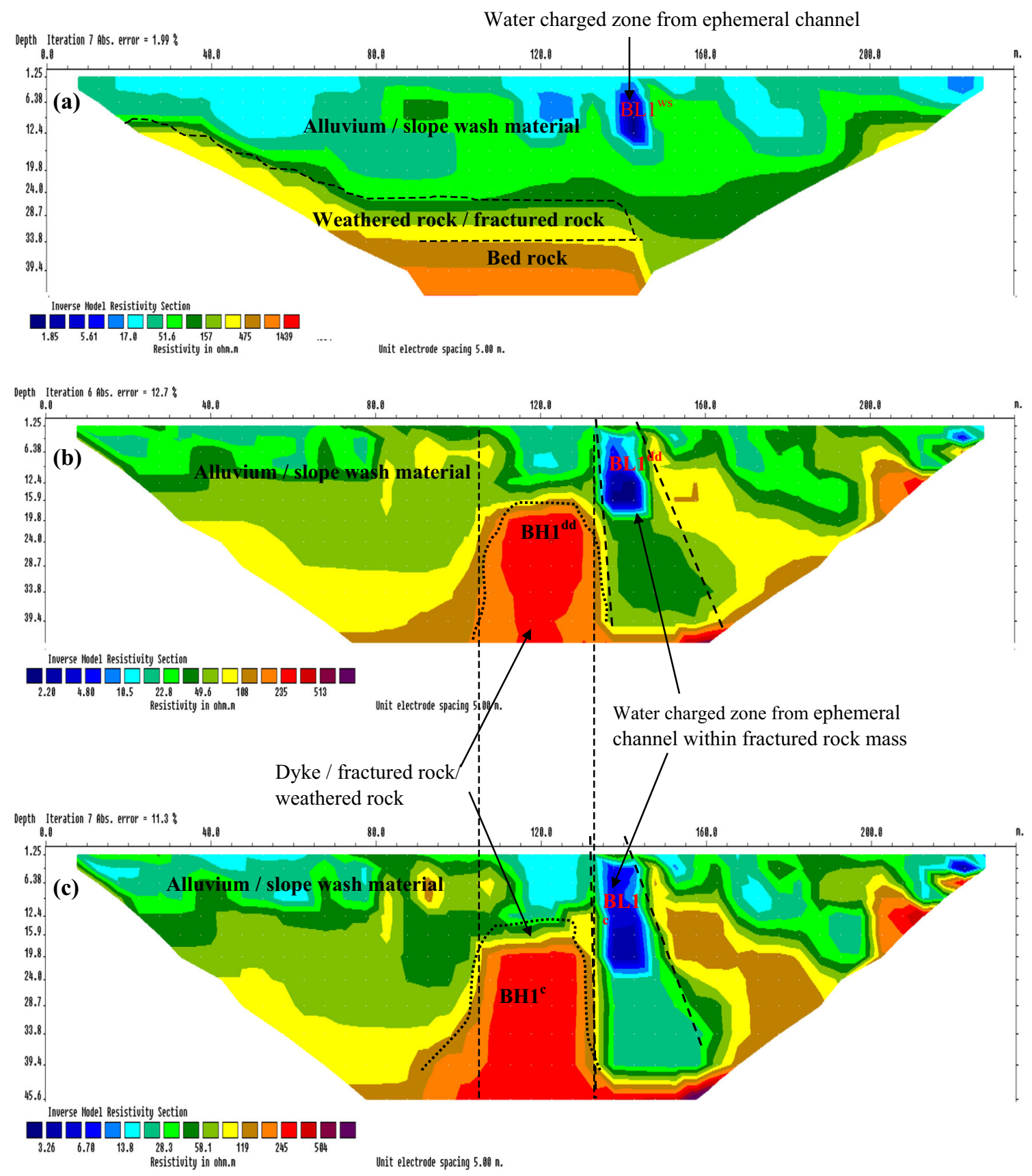

Figure 4. 2D ERT section along profile $\mathrm{BB}^{\prime}$ over the lower ground near Basti: (a) Wenner-Schlumberger array, (b) dipole-dipole array and (c) inversion of the cumulative data of both arrays with a quality factor 5 .

of the cumulative data of both dipole-dipole and Wenner-Schlumberger data sets (figure 4c).

\subsection{General discussions}

It is observed from both profiles $\mathrm{AA}^{\prime}$ and $\mathrm{BB}^{\prime}$ that horizontal features have been delineated well in 2D geoelectric generated by the Wenner-Schlumberger array but it is poor for resolving vertical structures (Dahlin and Zhou 2004, 2006; Loke 2004; Das et al. 2017). Whereas the dipole-dipole array is quite good to resolve the vertical resistivity variation. From figures 3 and 4 , it is found that generally all the resistivity signatures associated with different subsurface features have been delineated using the inversion of the cumulative data of both arrays (figures 3c and 4c). As such, any single array hardly delineates all signatures. As a whole, the resistivity signatures delineated by the inversion of the cumulative data of both arrays are mostly the combination of the features of each array. It is also observed that the $2 \mathrm{D}$ geoelectric section generated 
by the inversion of the cumulative data of both arrays provides greater in-depth investigation than any single array. These results are consistent with the earlier observation indicating that the inversion of cumulative data of multi array data sets provides collective advantages of all arrays with superior results (De la Vega et al. 2003; Stummer et al. 2004; Athanasiou 2004; Athanasiou et al. 2007; Bharti et al. 2016a, b). It is already theoretically established that combined data sets coming from different geoelectric arrays carry supplementary information compared with the individual data sets. De la Vega et al. (2003) conducted a study for gasoline contaminated soil using Wenner and dipole-dipole arrays. Furthermore, they used both the data sets for combined inversion, which results in superior in-depth investigation and better lateral resolution compared to the inversion results obtained from each array separately

\section{Conclusions}

From profile $\mathrm{AA}^{\prime}$, the low-resistivity features AL1 and AL2 have been delineated with the lowresistivity range $(\sim 10$ to $\sim 80 \Omega \mathrm{m})$ in all three different techniques (i) Wenner-Schlumberger array $\mathrm{AL}^{\mathrm{ws}}$, (ii) dipole-dipole array $\left(\mathrm{AL} 1^{\mathrm{dd}}\right.$ ) and (iii) inversion of the cumulative data of both arrays $\left(\mathrm{AL} 1^{\mathrm{c}}\right)$. However, AL3 has been delineated with the low-resistivity range $(\sim 10$ to $\sim 50 \Omega \mathrm{m})$ using (i) the dipole-dipole array (AL3 ${ }^{\mathrm{dd}}$ ) and (ii) inversion of cumulative data of both arrays $\left(\mathrm{AL}^{\mathrm{C}}{ }^{\mathrm{C}}\right)$. All these low-resistivity features indicate moist soil water saturated alluvium/aquifer. A high-resistivity feature AH1 identified in the Wenner-Schlumberger array $\left(\mathrm{AH} 1^{\mathrm{ws}}\right)$ and inversion of cumulative data of both arrays $\mathrm{AH} 1^{\mathrm{c}}$, inferred to be a dyke-like structure

From profile $\mathrm{BB}^{\prime}$, the low-resistivity feature BL1 has been delineated with the low-resistivity range ( $\sim 1$ to $\sim 15 \Omega \mathrm{m})$ in all three different techniques (i) Wenner-Schlumberger array BL1 ${ }^{\text {ws }}$, (ii) dipoledipole array $\left(B L 1^{\mathrm{dd}}\right.$ ) and (iii) inversion of the cumulative data of both arrays $\mathrm{BL} 1^{\mathrm{c}}$, which indicate water saturated clayey formation. The spreading out of BL1 to the greater depth with a larger horizontal expansion indicates a water-saturated fracture zone. Interestingly, it is well correlated with the surficial location of an ephemeral channel at the bottom of the hill across the slope. It is observed that the low-resistivity feature (BL1 ${ }^{\text {ws }}$ ) delineated in the Wenner-Schlumberger array is limited to a shallow depth only, which indicates a relatively deeper extension using dipole-dipole $\left(B L 1^{\mathrm{dd}}\right)$. However, this is well delineated to a greater depth and horizontal extension using the inversion of the cumulative data of both arrays $\left(\mathrm{BL} 1^{\mathrm{dd}}\right)$. A high-resistivity feature BH1 identified in the dipole-dipole array $\left(\mathrm{BH}^{\mathrm{dd}}\right)$ and the inversion of cumulative data of both arrays $\mathrm{BH} 1^{\mathrm{c}}$, inferred to be a dyke-like structure. The present study reveals that the geoelectric sections generated by the inversion of the cumulative data of both arrays provides superior results, which delineates all features with a greater depth of investigation

\section{Acknowledgements}

The authors are thankful to SERB, DST, Government of India for funding the project (PDF/2016/004034). The authors wish to thank the director, IIT (ISM) Dhanbad and the director, CSIR-CIMFR, Dhanbad, for their support to this study. The authors are also thankful to Prof M Radhakrishna, Associate Editor and to an anonymous reviewer for their valuable suggestions.

\section{References}

Athanasiou E 2004 Combined inversion of geoelectrical data by the use of contact electrodes; MSc Thesis, Aristotle University of Thessaloniki.

Athanasiou E N, Tsourlos P I, Papazachos C B and Tsokas G N 2007 Combined weighted inversion of electrical resistivity data arising from different array types; J. Appl. Geophys. 62 124-140.

Banerjee K S, Sharma S P, Sarangi A K and Sengupta D 2011 Delineation of subsurface structures using resistivity, VLF and radiometric measurement around a Utailings pond and its hydrogeological implication; Phys. Chem. Earth 36 1345-1352.

Bharti A K, PalS K, Priyam P, Narayan S, Pathak V K and Sahoo S D 2015 Detection of illegal mining over Raniganj coalfield using electrical resistivity tomography; Engineering geology in new millennium, New Delhi, 27 to 29 October.

Bharti A K, Pal S K, Priam P, Kumar S, Shalivahan S and Yadav P K 2016a Subsurface cavity detection over Patherdih colliery, Jharia coalfield, India using electrical resistivity tomography; Environ. Earth Sci. 755 1-17.

Bharti A K, Pal S K, Priam P, Pathak V K, Kumar R and Ranjan S K 2016b Detection of illegal mine voids using electrical resistivity tomography: The casestudy of Raniganj coalfield India; Eng. Geol. 213 120-132.

Bharti A K, Pal S K, Ranjan S K, Priyam P and Pathak V K 2016c Coal mine cavity detection using electrical resistivity tomography: A joint inversion of multi array data; In: 22nd European meeting of environmental and engineering 
geophysics; EAGE, Barcelona, Spain, https://doi.org/10. 3997/2214-4609.201602084.

Bhattacharya P K and Patra H P 1968 Direct current geoelectric sounding: Principles and interpretation; In: Methods in Geochemistry,Geophysics Series, vol. 9, Elsevier Publishing Company, pp 135.

Bhattacharya B B and Shalivahan S 2016 Geoelectric methods: Theory and application; McGraw Hill Education, $735 \mathrm{p}$.

Biswas A, Jana A and Sharma S P 2012 Delineation of groundwater potential zones using satellite remote sensing and geographic information system techniques: A case study from Ganjam district, Orissa; Res. J. Recent Sci. 1 9, 59-66.

Biswas A, Jana A and Mondal A 2013 Application of remote sensing, GIS and MIF technique for elucidation of groundwater potential zones from a part of Orissa coastal tract, Eastern India; Res. J. Recent Sci. 211, 4249.

Cardarelli E, Cercato M, Cerreto A and Di Filippo G 2010 Electrical resistivity and seismic refraction tomography to detect buried cavities; Geophys. Prospect. 58 685695.

Chandra S, Ahmed S, Ram A and Dewandel B 2008 Estimation of hard rock aquifers hydraulic conductivity from geoelectrical measurements: A theoretical development with field application; J. Hydrol. 357 218-227.

Dahlin T and Zhou B 2004 A numerical comparison of 2D resistivity imaging with 10 electrode arrays. Geophys Prospect 52:379-398. https://doi.org/10.1111/j. 1365-2478.2004.00423.x

Dahlin T and Zhou B 2006 Multiplegradient array measurements for multichannel 2D resistivity imaging; Near Surf. Geophys. 4 113-123.

Das P and Mohanty P R 2016 Resistivity imaging technique to delineate shallow subsurface cavities associated with old coal working: A numerical study; Environ. Earth Sci. 75661.

Das P, Pal S K, Mohanty P R, Priyam P, Bharti A K and Kumar R 2017 Abandoned mine galleries detection using electrical resistivity tomography method over Jharia coal field, India; J. Geol. Soc. India 902 169-174.

De la Vega M, Osella A and Lascano E 2003 Joint inversion of Wenner and dipole-dipole data to study a gasolinecontaminated soil; J. Appl. Geophys. 54 97-109.

Dutta S, Krishnamurthy N S, Rao T A V A, Ahmed S and Baltassat J M 2006 Localization of water bearing fractured zones in a hard rock area using integrated geophysical techniques in Andhra Pradesh, India; Hydrologeol. J. 14 760-766.

Giao P H, Chung S G, Kim D Y and Tanaka H 2003 Electric imaging and laboratory resistivity testing for geotechnical investigation of Pusan clay deposits; J Appl. Geophys. 52 157-175.

Jha R 2014 Analysis of groundwater potential zones using electrical resistivity, RS \& GIS techniques in a typical mine area of Odisha; A Dissertation Submitted in partial fulfilment of the requirements for the award of the Degree of Master of technology in Civil Engineering with specialisation in water resources engineering.

Karous M and Mares S 1988 Geophysical methods in studying fracture aquifers; Charles University, Prague, p. 93.
Krishnamurthy N S, Kumar D, Rao A V, Jain S C and Ahmed S 2003 Comparison of surface and subsurface geophysical investigations in delineating fracture zones; Curr. Sci. 849 1242-1246.

Kumar D 2012 Efficacy of electrical resistivity tomography technique in mapping shallow subsurface anomaly; J. Geol. Soc. India 80 304-307.

Kumar D, Ahmed S, Krishnamurthy N S and Dewandel B 2007 Reducing ambiguities in vertical electrical sounding interpretations: A geostatistical application; J. Appl. Geophys. 62 1, 16-32.

Kumar D, Rao V A and Sarma V S 2014 Hydrogeological and geophysical study for deeper groundwater resource in quartzitic hard rock ridge region from $2 \mathrm{D}$ resistivity data; J. Earth Syst. Sci. 123 3, 531-543.

Kumar D, Mondal S, Nandan M J, Harini P, Sekhar S B M V, Sen M K, Keller G V and Frischknecht F C 2016 Two-dimensional electrical resistivity tomography (ERT) and time-domain-induced polarization (TDIP) study in hard rock for groundwater investigation: A case study at Choutuppal Telangana, India, India; Arab. J. Geosci. 9 355.

Leucci G 2006 Contribution of ground penetrating radar and electrical resistivity tomography to identify the cavity and fractures under the main church in Botrugno Lecce, Italy; J. Archaeol. Sci 33 1194-1204.

Loke M H 1999 Electrical imaging surveys for environmental and engineering studies a practical guide to $2-\mathrm{D}$ and $3-\mathrm{D}$ surveys, pp67.

Loke M H 2004 Tutorial: 2-D and 3-D Electrical Imaging Surveys. p. 128.

Loke M H and Barker R D 1996 Rapid leastsquares inversion of apparent resistivity pseudosections by a quasi-Newton method; Geophys. Prospect. 44 131-152.

Martínez-Moreno F J, Galindo-Zaldívar J, Pedrera A, Teixido T, Ruano P, Peña J A, González-Castillo L, RuizConstán A, López-Chicano M and Martín-Rosales W 2014 Integrated geophysical methods for studying the karst system of Gruta de las Maravillas Aracena, Southwest Spain; J. Appl. Geophys. 107 149-162.

Mishra S and Johnson P T 2005 Geochronological constraints on evolution of the singhbhum Mobile belt and associated basic volcanics of Eastern Indian Shield; Gondwana Res. 8 129-142.

Mohammed S F 2011 Geophysical characteristics of Wadi Hanifah water system, Riyadh, Saudi Arabia; Arab. J. Geosci. 4 1051-1066.

Mondal N C, Singh V and Ahmed S 2013 Delineating shallow saline groundwater zones from Southern India using geophysical indicators; Environ. Monit. Assess. 1856 4869-4886.

Parasnis DS 1986 Principles of applied geophysics (4th edn); Chapman and Hall, London, UK, 402p.

Rai S N, Thiagarajan S, Shankar G B K, Kumar M S, Venkatesa V, Mahesh G and Rangarajan R 2015 Groundwater prospecting in Deccan traps covered Tawarja basin using electrical resistivity tomography; J. Indian Geophys. Union 193 256-269.

Saraf A K and Chowdhury P R 1998 Integrated remote sensing and GIS for groundwater exploration and identification of artificial recharge sites; Int. J. Remote Sens. 19 10, 1825-1841. 
Sarma V S 2014 Electrical resistivity ER, selfpotential SP, induced polarisation IP, spectral induced polarisation (SIP) and electrical resistivity tomography (ERT) prospection in NGRI for the past 50 years: A brief review; J. Ind. Geophys. Union 182 245-272.

Saxena V K, Mondal N C, Singh V S and Kumar D 2005 Identification of waterbearing fractures in hard rock terrain by electrical conductivity logs, India; Environ. Geol. 48 1084-1095.

Sharma S P and Baranwal V C 2005 Delineation of groundwater-bearing fracture zone in a hardrock area integrating very Low frequency electromagnetic and resistivity data; J. Appl. Geophys. 57 155-166.

Shishaye H A and Abdi S 2016 Groundwater exploration for water well site locations using geophysical survey methods; Hydrol. Curr. Res. 71, 7-226.

Singh K K K 2013b Delineation of waterlogged area in inaccessible underground workings at hingir rampur colliery using 2D resistivity imaging: A case study; Bull. Eng. Geol. Environ. 721, 115-118.

Singh K K K, Singh K B, Lokhande R D and Prakash A 2004 Multielectrode resistivity imaging technique for the study of coal seam; J. Sci. Ind. Res. 63 927-930.

Srivastava V K, Giri D N and Bharadwaj P 2012 Study and mapping of ground water prospect using remote sensing,
GIS and geoelectrical resistivity techniques - A case study of Dhanbad district, Jharkhand, India; J. Ind. Geophys. Union 162, 55-63.

Stummer P, Maurer H and Green A 2004 Experimental design: Electrical resistivity data sets that provide optimum subsurface information; Geophysics 69 120-139.

Surinaidu L, Gurunadha R V V S, Tamma R G, Mahesh J, Padalu G, SarmaV S, Rajendra P P, Mallikarjuna R S and Manga R R B 2012 An integrated approach to investigate saline water intrusion and to identify the salinity sources in the Central Godavari delta, Andhra Pradesh, India; Arab. J. Geosci., https://doi.org/10.1007/ s12517-012-0634-2.

Telford W M, Geldart L P, Sheriff R E and Keys D A 1976 Applied geophysics; Cambridge University Press.

Yadav G S and Singh S K 2007 Integrated resistivity surveys for delineation of fractures for groundwater exploration in hard rock areas; J. Appl. Geophys. 62 301-312.

Zhou B and Greenhalgh S A 2000 Crosshole resistivity tomography using different electrode configurations; Geophys. Prospect. 48 887-912.

Zohdy A A R, Eaton G P and Mabey D R 1974 Application of surface geophysics to groundwater investigation, techniques of water resources investigations, US Geol. Surv., $116 \mathrm{p}$.

Corresponding editor: Munukutla RAdHakrishna 